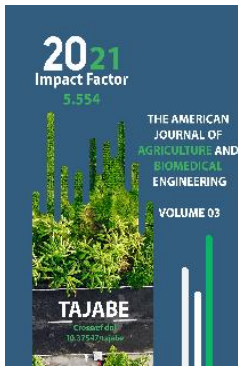

\title{
The Effect Of The Trichoderma Fungus On The Fertility Of Plants
}

Mamadiyev Khusanboy Ganijonovich

Lecturer, Andijan State Medical Institute, Andijan, Uzbekistan

Copyright: Original content from this work may be used under the terms of the creative commons attributes 4.0 licence.

\section{ABSTRACT}

Trichoderma, a soil fungus, is widespread in nature and is noted as a microbiological object that is easily separated, has a very rapid biomass formation and has a high level of biological activity against phytopathogenic fungi without harming the plant. Therefore, it is recommended to widely use the results of modern studies of metabolites of the producer Trichoderma Pers.: Fr, which exhibits several fungicidal actions, especially in the process of hyperparasitism in agriculture.

\section{KEYWORDS}

Trichoderma, microbiological diseases, environmental degradation, pests, fungi, biologically active substances.

\section{INTRODUCTION}

It is known that the Republic of Uzbekistan is a country specializing in the agricultural sector, with favourable climatic conditions suitable for high yields of almost all types of crops. In the absence of large losses in the process of cultivation and storage of agricultural products, this amount of land would be enough to provide the population of the Republic with food and technical raw materials and to export some of the products. During the cultivation of agricultural products in our country, as a result of various pests and microbiological diseases, $20-30 \%$ of crops are lost. Practical experience shows that the yield 
of crops is lost from $10 \%$ to $50 \%$ as a result of the development of some highly harmful microorganisms [1,2]. Such large losses in agriculture are also caused by pests and diseases that occur in crops.

The fact that more than 220 species of pests have been reported to be infested by insects and diseases in the growth and development of cotton also indicates the urgency of combating these pests. Such highly harmful organisms can be infested by pests such as locusts, tapeworms, spiders. Scientific sources state that more than 150 pests damage organisms during the cultivation of cereals.

In particular, many studies have shown that the yield of a single grain is lost from $5 \%$ to $50 \%$ under the influence of pests during storage. In the territory of the Republic of Uzbekistan, harmful weeds are growing and causing significant damage to grain crops, especially wheat in the Fergana Valley, Tashkent, Samarkand, Jizzakh, Syrdarya, Bukhara, Navoi and Surkhandarya regions. It is known that the germination of seed grain obtained from areas affected by weeds is reduced by up to 50 per cent. Also, the quality of flour made from damaged grain is causing huge problems in the food industry.

The deterioration of the ecological situation, soil microflora, its physicochemical composition, pollution of water bodies, which in recent years has become one of the most pressing problems, resulting in severe adverse effects on humans and warm-blooded animals, limits the use of chemicals. Such problems pose challenges to scientists, such as the development and practical application of alternative methods of pest and disease control. One of the 6 alternative methods is pest and disease control based on microbiological drugs. This method has several advantages over the chemical method, including environmental friendliness, nonaccumulation in the soil, ease of preparation, storage, transportation and application, economic efficiency, and relative safety, especially in warm-blooded animals.

\section{MATERIALS AND METHODS}

Trichoderma, a soil fungus, is widespread as a microbiological object that is easy to separate cleanly produces biomass very quickly, has a high biological activity against phytopathogenic fungi without harming plants, and can synthesize biologically active substances that control plant growth. is recorded. Therefore, it is advisable to use the results of modern research on metabolites of Trichoderma Pers.: Fr, which exhibits a range of fungicidal action, especially the process of hyperparasitism in agriculture and the possibility of synthesizing plant growth control agents.

Therefore, in our subsequent research, we tried to study the phytohormone synthesis property of the Trichoderma fungus. We believe that this will allow us to create a new generation of bio preparation in the future. Because the hyperparasitic property of the Trichoderma fungus has been widely used by scientists until now, data on their metabolites that control plant growth are rare in scientific sources. The main goal of these studies was to study the factor that accelerates the growth of the amaranth plant of the fungus Trichoderma. We, therefore, aimed to analyse the composition of the metabolic substances produced by the Trichoderma fungus to control plant growth. In scientific sources, data have emerged that the dry biomass of the plant Vaccinium corymbosum $L$. inoculated with the strain of Trichoderma harsianum Rifai increased by 2-3-fold [3]. 
Complex effects are required to stimulate plant growth and development, including auxins produced by fungi that also have a significant effect on plants $[4,5,6]$. Auxin - indolyl-3-acetic acid (IAA) - is also very important in this, participating directly in the symbiosis of plants and bees with several enzymes and secondary metabolites that it produces $[7,8]$. It should be noted that the ability to synthesize IAA varies from tens of times to hundreds of times in different fungi, even strains [9]. Also, fungi synthesize IAA using tryptophan as a derivative [4].

Therefore, their formation of auxins has a significant effect on the amount of release of this amino acid in the plant host. Therefore, in our studies, we aimed to study the amount of IAA produced by the Trichoderma fungus to control plant growth and the effect of the amino acid L-tryptophan on its formation. The research work was carried out in the following order, photocalometric screening was performed to study the indole-3-acetic acid synthesis properties of the strains. Strains were transplanted into Chapek nutrient media with L-tryptophan and grown at $7{ }^{\circ} \mathrm{C}$ for 7 days. The cultured cultures were filtered, $2 \mathrm{ml}$ of supernatant was obtained, mixed with $8 \mathrm{ml}$ of Salkovsky reagent $\left(50 \mathrm{ml}, 35 \% \mathrm{HClO}_{4} ; 1 \mathrm{ml}\right.$ of 0.5 $\mathrm{M} \mathrm{FeCl}_{3}$ ) and left for 20-30 minutes. Samples with IAA produce a reddish-pink colour. Then, the optical density was checked using a green light filter at a wavelength of $530 \mathrm{~nm}$ FEK - KFK2 (Russia) [10]. The amount of IAA in the samples was calculated based on a standard curve.

Trichoderma, a soil fungus, is widespread as a microbiological object that is easy to separate cleanly produces biomass very quickly, has a high biological activity against phytopathogenic fungi without harming plants, and has the ability to synthesize biologically active substances that control plant growth. is recorded. Therefore, it is advisable to use the results of modern research on metabolites of Trichoderma Pers.: Fr, which exhibits a range of fungicidal action, especially the process of hyper parasitism in agriculture and the possibility of synthesizing plant growth control agents. Therefore, in our subsequent research, we tried to study the phytohormone synthesis property of the Trichoderma fungus. We believe that this will allow us to create a new generation of bio preparation in the future. Because the hyperparasitic property of the Trichoderma fungus has been widely used by scientists until now, data on their metabolites that control plant growth are rare in scientific sources. The main goal of these studies was to study the factor that accelerates the growth of the amaranth plant of the fungus Trichoderma. We, therefore, aimed to analyse the composition of the metabolic substances produced by the Trichoderma fungus to control plant growth.

In scientific sources, data have emerged that the dry biomass of the plant Vaccinium corymbosum L. inoculated with the strain of Trichoderma harsianum Rifai increased by 2-3fold [3]. Complex effects are required to stimulate plant growth and development, including auxins produced by fungi that also have a significant effect on plants [11-14]. Auxin - indolyl-3-acetic acid (IAA) - is also very important in this, participating directly in the symbiosis of plants and bees with several enzymes and secondary metabolites that it produces [15-17]. It should be noted that the ability to synthesize IAA varies from tens of times to hundreds of times in different fungi, even strains [18-19]. In addition, fungi synthesize IAA using tryptophan as a derivative [4].

Therefore, their formation of auxins has a significant effect on the amount of release of this amino acid in the plant host. Therefore, in our studies, we aimed to study the amount of IAA produced by the Trichoderma fungus to control plant growth and the effect of the amino acid L-tryptophan on its formation. 
The American Journal of Agriculture and Boimedical Engineering

(ISSN - 2689-1018)

IMPACT FACTOR

Published: March 26, 2021| Pages: 17-23

Doi: https://doi.org/10.37547/tajabe/Volume03Issue03-04

2021: $5 \cdot 554$

OCLC - 1121105746

The research work was carried out in the following order, photocalometric screening was performed to study the indole-3-acetic acid synthesis properties of the strains. Strains were transplanted into Chapek nutrient media with L-tryptophan and grown at $7{ }^{\circ} \mathrm{C}$ for 7 days. The cultured cultures were filtered, $2 \mathrm{ml}$ of supernatant was obtained, mixed with $8 \mathrm{ml}$ of Salkovsky reagent $\left(50 \mathrm{ml}, 35 \% \mathrm{HClO}_{4} ; 1 \mathrm{ml}\right.$ of 0.5 $\mathrm{M} \mathrm{FeCl}_{3}$ ) and left for 20-30 minutes. Samples with IAA produce a reddish-pink colour. Then, the optical density was checked by means of a green light filter at a wavelength of $530 \mathrm{~nm}$ "FEK - KFK-2" (Russia) [10]. The amount of IAA in the samples was calculated based on a standard curve.
For the identification of IAA, studies were performed using the method of thin-layer chromatography (TLC). To do this, the ethyl acetate fraction was instilled into silica gel plates (Silica gel G $f 254$, thickness $0.25 \mathrm{~mm}$ ). It was then treated with ethyl acetate: chloroform: formic acid (55:35:10) or benzene: butanol: acetic acid (70: 25: 5) [18-24]. It is known that a homogeneous $\mathrm{Rf}$ value with a standard IAA indicates that an IAA is present in the supernatant. Table 1 shows that the amount of tryptophan has a significant effect on the synthesis of indole-3-acetic acid (IAA) when Trichoderma fungi are grown in a liquid medium in different ways.

Table 1. The effect of tryptophan on the synthesis of indole-3-acetic acid (IAA) when growing the fungus Trichoderma in a liquid nutrient medium by various methods

\begin{tabular}{|c|c|c|}
\hline $\begin{array}{c}\text { The amount of } \\
\text { tryptophan in the } \\
\text { feed, } \mathrm{mM}\end{array}$ & $\begin{array}{c}\text { The amount of IAA in the } \\
\text { culture fluid when shaken, } \\
\text { mkM }\end{array}$ & $\begin{array}{c}\text { The amount of IAA in the } \\
\text { culture fluid at stationary } \\
\text { cultivation, mkM }\end{array}$ \\
\hline 0 & 18.2 & 15.2 \\
\hline 0.5 & 18.4 & 24.2 \\
\hline 1.0 & 22.6 & 22.4 \\
\hline 1.5 & 28.6 & 26.6 \\
\hline 2.0 & 30.2 & 26.8 \\
\hline 2.5 & 32.2 & 41.2 \\
\hline 3.0 & 32.6 & 46.4 \\
\hline 3.5 & 33.4 & 54.2 \\
\hline 4.0 & 34.2 & 58.3 \\
\hline 4.5 & 34.4 & 58.6 \\
\hline 5.0 & 34.4 & 60.2 \\
\hline
\end{tabular}

In this case, the method of cultivation was carried out under two different conditions: in the usual way the culture medium was shaken, and the liquid medium was carried out in a stationary state. The results showed that when the amount of tryptophan was $2.5 \mathrm{mM}, 32.2 \mu \mathrm{M}$ IAA was produced in the liquid culture medium, while in the same amount of tryptophan, 41.2 $\mu \mathrm{M}$ IAA was produced in the culture fluid when grown in stationary conditions. Interestingly, when tryptophan levels were determined from $4.0 \mathrm{mM}$ to $5.0 \mathrm{mM}$, it was noted that IAA formation did not change after 34.2-34.4 $\mu \mathrm{M}$ under conditions in which the liquid nutrient medium was cultured. The opposite was observed in the second growing condition. In particular, when tryptophan was added to the culture medium in the amount of 4.0-5.0 mM, 
The American Journal of Agriculture and Boimedical Engineering (ISSN - 2689-1018)

the formation of IAA by the method of stationary cultivation increased from $58.3 \mu \mathrm{M}$ to $60.2 \mu \mathrm{M}$.

Therefore, it is advisable to pay attention to the growing conditions and the amount of tryptophan in the preparation of a bio preparation that controls the growth of plants from the fungus Trichoderma in the form of culture fluid. In our subsequent studies, the possibilities of IAA formation of fungal biomass in a nutrient medium were considered (Table 2).

Table 2. Effect of tryptophan content on IAA synthesis of Trichoderma fungal biomass in a nutrient medium

\begin{tabular}{|c|c|}
\hline $\begin{array}{c}\text { The amount of tryptophan in the } \\
\text { feed, } \mathrm{mM}\end{array}$ & $\begin{array}{c}\text { The auxin-forming activity of mycelial mass, } \mathrm{mkg} \\
\text { IAA/g biomass }\end{array}$ \\
\hline 0 & 189.6 \\
\hline 0.5 & 225.2 \\
\hline 1.0 & 268.4 \\
\hline 1.5 & 275.8 \\
\hline 2.0 & 300.6 \\
\hline 2.5 & 336.2 \\
\hline 3.0 & 362.4 \\
\hline 3.5 & 392.6 \\
\hline 4.0 & 466.4 \\
\hline 4.5 & 520.4 \\
\hline 5.0 & 525.2 \\
\hline
\end{tabular}

The results show that in this case, too, the amount of tryptophan in the nutrient medium was noted as a major factor. During the study, it was observed that the amount of tryptophan in the nutrient medium remained quantitatively unchanged in the range of 4.5$5.0 \mathrm{mM}$, the formation of IAA (520.4-525.2 mcg IAA/g biomasses). Therefore, during the preparation of a bio preparation in the liquid state based on the fungus Trichoderma, it is necessary to use stationary growing conditions and to achieve the content of L-tryptophan amino acid in the amount of 4.5-5.0 $\mathrm{mM}$ in the liquid nutrient medium. Then it will be possible to prepare the desired amount of IAAcontaining bio preparation.

\section{CONCLUSION}

Trichoderma, a soil fungus, is widespread and is noted as a microbiological object that is easy to separate cleanly, has a very fast biomass formation, and has a high level of biological activity against phytopathogenic fungi without harming the plant. Therefore, it is advisable to make extensive use of the results of modern research on metabolites of the producer Trichoderma Pers.:Fr, which exhibits a range of fungicidal action, especially the process of hyperparasitism in agriculture. In the preparation of a bio preparation to control the growth of plants in the liquid state based on the fungus Trichoderma should use the conditions of the stationary culture of the culture and achieve the presence of Ltryptophan amino acid in the liquid medium in the amount of 4.5-5.0 mM. Then it will be 
possible to prepare the desired amount of IAAcontaining bio preparation.

\section{ACKNOWLEDGEMENTS}

The authors acknowledge the immense help received from the scholars whose articles are cited and included in references to this manuscript. The authors are also grateful to authors/ editors/publishers of all those articles, journals and books from where the literature for this article has been reviewed and discussed.

\section{REFERENCES}

1. Weidling R. Trichoderma lignorum as a parasite of soil fungi. (1932). Phytopath. 22(7). P. 837-845.

2. Lupashko-Stalsky, I.P. (2006). Food and Agriculture Organization of the United Nations (FAO): Background.

3. Arriagada, C., Manquel, D., Cornejo, P., Soto, J., Sampedro, I., \& Ocampo, J. (2012). Effects of the co-inoculation with saprobe and mycorrhizal fungi on Vaccinium corymbosum growth and some soil enzymatic activities. Journal of soil science and plant nutrition, 12(2), 283-294.

4. Tsavkelova, E. A., Klimova, S. Y., Cherdyntseva, T. A., \& Netrusov, A. I. (2006). Microbial producers of plant growth stimulators and their practical use: a review. Applied biochemistry and microbiology, 42(2), 117-126.

5. Ergashovich, K. A., Toshtemirovna, N. U., Rakhimovna, A. K., \& Abdullayevna, F. F. (2020). Effects of Microelements on Drought Resistance of Cotton Plant. International Journal of Psychosocial Rehabilitation, 24(2).
6. Sid Ahmed, A., Pérez-Sánchez, C., Egea, C., \& Candela, M. E. (1999). Evaluation of Trichoderma harzianum for controlling root rot caused by Phytophthora capsici in pepper plants. Plant pathology, 48(1), 5865.

7. Contreras-Cornejo, H. A., MacíasRodríguez, L., Cortés-Penagos, C., \& López-Bucio, J. (2009). Trichoderma virens, a plant beneficial fungus, enhances biomass production and promotes lateral root growth through an auxin-dependent mechanism in Arabidopsis. Plant physiology, 149(3), 1579-1592.

8. Vinale, F., Sivasithamparam, K., Ghisalberti, E. L., Marra, R., Woo, S. L., \& Lorito, M. (2008). Trichoderma-plantpathogen interactions. Soil Biology and Biochemistry, 40(1), 1-10.

9. Hoyos-Carvajal, L., Orduz, S., \& Bissett, J. (2009). Growth stimulation in bean (Phaseolus vulgaris L.) by Trichoderma. Biological control, 51(3), 409-416.

10. Hasan, H. A. H. (2002). Gibberellin and auxin production by plant root-fungi and their biosynthesis under salinity-calcium interaction. Rostlinna vyroba, 48(3), 101106.

11. Bae, Y. S., \& Knudsen, G. R. (2005). Soil microbial biomass influence on growth and biocontrol efficacy of Trichoderma harzianum. Biological Control, 32(2), 236242.

12. Howell, C. R. (2003). Mechanisms employed by Trichoderma species in the biological control of plant diseases: the history and evolution of current concepts. Plant disease, 87(1), 4-10.

13. Green, H., Larsen, J., Olsson, P. A., Jensen, D. F., \& Jakobsen, I. (1999). Suppression of 
the Biocontrol AgentTrichoderma harzianum by Mycelium of the Arbuscular Mycorrhizal Fungus Glomus intraradices in Root-Free Soil. Applied and Environmental Microbiology, 65(4), 1428-1434.

14. Harman, G. E. (2000). Myths and dogmas of biocontrol changes in perceptions derived from research on Trichoderma harzinum T-22. Plant disease, 84(4), 377393.

15. Nazirova, R., Usmonov, N., \& Askarov, K. (2020). Technology of storing grain in a cooled state. Збірник наукових праць

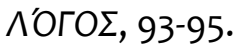

16. Chet, I. (1990). Mycoparasitismrecognition, physiology and ecology. New directions in biological control. Alternatives for suppressing agricultural pests and diseases. Proceedings of a UCLA colloquium held at Frisco, Colorado, January 20-27, 1989., 725-733.

17. Nazirova, R. M., Khoshimov, A. A., Tadjiyev, S. M., \& Mirsalimova, S. R. (2020). Investigation of solubility kinetics and interaction of stabilizing additive in production of complex fertilizers based on granular nitrate and stabilizing additives. Academicia an international multidisciplinary research journal, 10(5), 657-664.

18. Ergashovich, K. A., Davronovich, K. Y., Toshtemirovna, N. U., \& Azamatovna, B.Z. (2020). Effect of soil types, salinity and moisture levels on cotton productivity. Journal of Critical Reviews, 7(9), 240-243.

19. Elad, Y., Barak, R., Chet, I., \& Henis, Y. (1983). Ultrastructural studies of the interaction between Trichoderma spp. and plant pathogenic fungi. Journal of Phytopathology, 107(2), 168-175.
20. Inbar, J., \& Chet, I. (1994). A newly isolated lectin from the plant pathogenic fungus Sclerotium roltsii: purification, characterization and role in mycoparasitism. Microbiology, 140(3), 651657.

21. Mukhtarovna, N. R., Alimardonugli, S. A., \& Botiraliyevich, U. N. (2021). Features of treatment of winter wheat seeds by different processors. International Engineering Journal For Research \& Development, 6(ICDSIIL), 3-3.

22. Davronovich, K. Y., \& Ergashovich, K. A. (2019). Growing of cotton varieties and hybrid to the height under the ecological conditions of soil salinity and washed soil salinity. Asian Journal of Multidimensional Research (AJMR), 8(9), 84-89.

23. Mukhtarovna, N. R., \& Botiraliyevich, U. N. (2021, January). Role of sugar production waste in increasing the productivity of cattle. In Euro-Asia Conferences (Vol. 1, No. 1, pp. 346-349).

24. Kholliyev, A. E., Norboyeva, U. T., Kholov, Y. D., \& Boltayeva, Z. A. (2020). Productivity Of Cotton Varieties In Soil Salinity And Water Deficiency. The American Journal of Applied sciences, 2(10), 7-13. 